\title{
O conceito de direito (em seu aspecto lógico) aplicado ao direito econômico brasileiro (aspecto material)
}

\author{
Juliana Haddad Pereira ${ }^{1}$
}

\begin{abstract}
Resumo
0 conceito de direito em seu aspecto lógico alberga a possibilidade de universalização do conceito, no sentido de evidenciar um parâmetro formal universalizante à ser preenchido de acordo com os interesses e costumes de cada ordenamento social. É a base estrutural que necessariamente deverá preexistir à construção material do direito, por ser referência estrutural do dever-ser às ciências jurídicas que serão conteúdo inarredável do então aspecto material do direito. 0 presente artigo destina-se aprioristicamente a referendar o conceito lógicouniversal do direito como sendo sua estrutura fundamental ('o que é') para, num segundo momento apreciar as disciplinas jurídicas ('quais são') oriundas do espaço, Brasil, e tempo, desde 1988. Através da referida delimitação espaço-tempo, abordar-se-á 0 aspecto material do direito, observando quais as contribuições de conteúdo que as referências nucleares do conceito formal universalizado foram capazes de construir em benefício e orientação do direito material. Em virtude da especificidade temática em apreço, não sendo possível verificar todas as contribuições 'materiais' advindas da referência estrutural fundamental, no Brasil a partir de 1988, o ensaio destinar-se-á humildemente a apreciação das contribuiç̧ões 'em espécie' que o aspecto lógico do conceito de direito realizou para a construção do direito econômico, reunindo um breve conjunto de autores que se propôs a identificação do direito econômico, bem como delimitação de seu conteúdo, e principalmente sua conformidade com a principiologia fundamental, tendo em vista ser o direito econômico uma disciplina jurídica necessária e bem vinda ao atual regime político social e econômico.
\end{abstract}

Palavras-Chave: Conceito de direito; Aspecto formal; Aspecto material; Direito econômico.

\section{Introdução}

Apresentadas e conhecidas as conformidades do aspecto lógico do conceito de direito, sob o ponto de vista do professor Lourival Vilanova, que por sua vez referenda, dentre outros, ensaios de Kelsen, Kant e Husserl, surgem as ciências jurídicas, ou à quem prefira tratá-las como disciplinas jurídicas cada qual com sua esfera de atuação, conteúdo e

\footnotetext{
${ }^{1}$ Bacharel em Direito graduada em 2007 pela PUC/PR, Campus Londrina, aluna do Projeto de Pesquisa "ESTADO E RELAÇÕES EM PRESARIAIS; DIÁLOGOS FILOSÓFICOS E JURÍDICOS DIANTE DA REGULAÇÃO ESTATAL SOBRE A ORDEM ECONÔMICA NACIONAL". Universidade Estadual de Londrina. Este Artigo é resultado dos estudos realizados no referido Projeto de Pesquisa em sua primeira fase, 2007.
} 


\section{0 conceito de direito (em seu aspecto lógico) aplicado ao direito econômico brasileiro (aspecto material)}

demais particularidades. Se o conceito universal de direito é necessariamente formal, característica essa do aspecto lógico, as disciplinas jurídicas como sendo ramos autônomos do referido conceito de direito, tem natureza necessariamente material uma vez que produzem seus efeitos no universo das relações humanas.

Assim, em plena observância ao chamado 'núcleo identidade' que as disciplinas jurídicas devem manter com a norma fundamental, como Kelsen preferiu chamar o conceito de direito em seu aspecto lógico ou universal, o comportamento de cada ciência, por assim dizer deflagra algumas evidencialidades acerca da positiva conexão do direito material com o direito formal. Atenta para o fato de que para produzir efeitos válidos no universo das realizações do homem, além da delimitação de espaço- tempo, profundamente conveniente e necessária, não basta que se conheçam as concepções do real, do fático e dos interesses oriundos da necessidade latente. É preciso que todos os apontamentos do ordenamento social passem por um processamento, uma triagem para que seja evidenciada sua relevância jurídica. Nesse processo seletivo obrigatoriamente pairam valores e princípios oriundos do conceito lógico- formal de direito, qual seja a norma fundamental. Desta forma, não há ciência jurídica (aspecto material do direito) que se sustente longe dos valores emanados da norma fundamental (aspecto lógico formal do direito).

0 presente artigo objetiva demonstrar a validade das aludidas afirmações na esfera do direito econômico. Como se construiu e se delimitou o conteúdo dessa disciplina jurídica em observância aos axiomas universais preponderantes do aspecto lógico do conceito de direito e como todos devemos nos orientar diante das concepções do direito econômico, ou seja, de que forma o Legislador, o Jurista, o Poder Executivo e o Particular em si devem interpretar os desígnios do direito econômico sem que haja uma ruptura com as nuances fundamentalizantes e universais.

Cabendo inclusive destacar que a própria construção do direito econômico tomou o devido cuidado de estabelecer em torno do fato econômico, uma ordem econômica cuja tábua de valores reverencia a norma fundamental.

\section{0 conceito de direito em seu aspecto lógico}

Segundo os escritos do professor Lourival Vilanova (2003, p. 36), interessa-nos destacar para a presente proposta, que o conceito de direito reserva uma porção que 
evidencia aquilo que todas as disciplinas jurídicas têm em comum. Existe entre a multiplicidade de fatores que constroem cada ramo do direito, uma vertente que se mantém, havendo, portanto um fator de homogeneidade a ser cuidadosamente apreciado.

O autor busca uma forma cristalina de conduzir seu intento à propositura de um conceito universal de direito. Para tanto, atenta que somente é possível referida concepção em caráter formal, ou seja, estrutural para que não haja comprometimento do resultado a que se propõem. Seleciona dentro do positivismo filosófico, a lógica como instrumento para detalhar as formas e estruturas do conjunto de valores do dever-ser, capazes de serem universalmente considerados para o conceito de direito:

[...] diante da universalidade do conceito do direito quer-se fixar um conceito de tal forma que se aplique em caráter absoluto a qualquer objeto ou fenômeno jurídico no tempo, para tanto, deve-se admitir que diante da diversidade de conteúdo encontra-se um núcleo substancial, um substrato essencial que se extrai do plano lógico que traz um conceito meramente formal. (VILANOVA, 2003, p. 36, grifo nosso-)

Assim, nasce para o conceito universal um conjunto de conceitos fundamentais para 0 dever-ser de capital importância na construção dos conceitos oriundos das ciências jurídicas em particular, sob pena destas não concretizarem a validez e a eficácia pretendidas.

Por exemplo, o conceito universal de direito, alberga a concepção de fato social. Dessa evidencialidade conceitual, dentro dos vários ramos do direito, verificam-se espécies diferentes de fatos sociais; políticos, religiosos, econômicos, etc. São estes conceitos derivados do conceito fundamental, restando claro que entre eles necessariamente há um vínculo de valores a ser perpetrado, "um substrato essencial que se extrai do plano lógico" .

Assim, o aspecto lógico do direito em sua função universalizadora deflagra sua superestrutura, o campo dos valores, como sendo essencial na verificação da situação fáticosocial da infra-estrutura, onde se encontra 0 aspecto material do direito.

Nesse sentido é que correrá a abordagem do direito econômico, como sendo um ramo do direito em seu aspecto material. Como ocorreu a delimitação de seu conteúdo e de que forma referida delimitação atendeu aos mandos do dever ser impostos pela carga valorativa do conceito de direito em seu aspecto lógico. 


\section{0 conceito de direito (em seu aspecto lógico) aplicado ao direito econômico brasileiro (aspecto}

material)

\section{0 conceito de direito em seu aspecto material}

Enquanto 0 aspecto formal emana parâmetros de valor a serem considerados pelas normas de condutas dirigidas a ordem social como um todo, o aspecto material se coloca diante dessa realidade social e metodologicamente a fragmenta. Subtrai o fato social e os sujeitos da relação jurídica, para então reunir o conjunto de normas específicas capazes de regulamentar e legitimar tais relações humanas.

Assim o faz no campo das relações econômicas: destaca as concepções acerca do fato econômico, os sujeitos da relação jurídica, quais sejam o Estado e os interesses privados, desenhando para referido ramo do direito uma ordem econômica, reconhecidas no tempo e no espaço, capaz de reger as relações econômicas em conformidade com o dever-ser axiológico advindo do aspecto formal do conceito de Direito.

\section{Conceito do direito (em seu aspecto lógico) aplicado ao direito econômico brasileiro (aspecto material)}

Em conformidade com todas as proposições destacadas até então, o Direito Econômico será analisado como sendo uma disciplina jurídica cujo conteúdo (aspecto material) foi criado e organizado de tal modo a exarar a impreterível observância e influênciabilidade dos axiomas jurídicos advindos do conceito de direito em seu aspecto formal.

O Direito Econômico, em um conceito amplo, é a ciência que se comprometeu a criar dispositivos normativos capazes de bem reger as relações econômicas entre o Estado e as unidades produtoras e distribuidoras, as Empresas, bem como regulamentar as relações econômicas advindas do relacionamento Empresa x Empresa (FONSECA, 2004, p. 16).

Essa esfera de normas que necessariamente foi se cristalizando ao redor das relações oriundas dos acontecimentos econômicos foram atraídas pelo interesse geral, pelo interesse peculiar dos produtores e distribuidores e pelos interesses particulares dos indivíduos, que além de interferir na relação econômica de forma mediata ou imediata, sentem os efeitos do comportamento admitido na mesma.

Com a evolução histórica que passou pelos Princípios da Igualdade e Liberdade da Revolução Francesa de 1789 e chegou à Concentração Econômica do Capitalismo 
Contemporâneo incitado no final da Guerra Fria, esses acontecimentos econômicos foram adquirindo características próprias capazes de transformá-los em um microssistema onde as normas jurídicas tornam-se cada vez mais específicas em resposta às pressões econômicas naturalmente refletidas (FONSECA, 2004, p. 17)

0 direito econômico acaba por focar o estudo do comportamento humano e das relações e fenômenos advindos do universo da atividade econômica, que por sua vez, nada mais é que o modo legitimado para adquirir recursos que financiarão 0 atendimento das necessidades humanas. A relação Direito - Economia, portanto, se faz na medida em que 0 primeiro realiza, quantitativa e qualitativamente, o teor normatizante capaz de gerir 0 equilíbrio dos interesses oriundos das necessidades sociais: quanto mais escassos os bens e aguçados os interesses sobre eles, maior quantidade e diversidade de normas se fazem necessárias para o equilíbrio de tais interesses (NUSDEO, 2005, p. 32).

Em observação aos apontamentos iniciais do presente ensaio, pode-se dizer que as concepções advindas do conceito de direito em seu aspecto formal, onde pairam os axiomas universalizantes, são gentilmente lançadas às relações econômicas que por sua vez, em virtude de seu alto grau de materialidade na seara econômica, atribuem a referidos conceitos uma vertente própria das relações de mercado contribuindo assim, para a edificação da disciplina jurídica de Direito Econômico.

Como parte do referido processo de construção da Ciência do Direito Econômico, cristalizou-se um protótipo acerca dos sujeitos que participam da relação econômica. De um lado está o Poder Econômico Privado, onde grupos procuram concentrar seu poder em busca de uma posição confortável de destaque e do outro se impõe o Estado, em defesa dos interesses da coletividade, cumpridor inarredável da função interventiva, no sentido de frear o interesse privado desmedido que por sua vez interfere na desestabilização do mercado como um todo (FONSECA, 2004b).

Para o professor Luis Cabral de Moncada o direito econômico pode ser definido como sendo o direito público da intervenção econômica do Estado, abrangendo todas as formas de intervenção na vida econômica. Explica que a lei dirigida ao Estado 'interventor' guarda vinculo com a Norma Fundamental (aspecto lógico) e que positiva a orientação política, o dever ser econômico, bem como o alto grau de comprometimento com o interesse geral. Além disso estabelece o professor que a ação do Estado é vinculada às 


\section{0 conceito de direito (em seu aspecto lógico) aplicado ao direito econômico brasileiro (aspecto material)}

normas que regem o sistema econômico (Lei 4595/64, do Sistema Financeiro Nacional por exemplo) orientando em especial as atividades dos agentes econômicos, que por sua vez ocupam a outra posição da relação econômica ora traduzida.

O Estado tem o dever de garantir com que a liberdade de concorrência e os valores sociais sejam unanimemente respeitados na relação econômica. É dele a responsabilidade de garantir a coexistência pacífica dos elementos econômicos com os elementos jurídicos. Para tanto, age de forma a estimular (art. 175, CF/88), normatizar (art. 174, CF/88) e até mesmo exercer (art. 173, CF/88) a atividade econômica primando pela efetivação dos valores mais elevados do Estado Brasileiro, a partir da Constituição Republicana de 1988.

Nesse diapasão verifica-se que o valor de justiça e de igualdade emanados do conceito de direito em seu aspecto lógico fazem-se presentes, no tempo e no espaço, para a construção do Direito Econômico. Das concepções universalizantes que o conceito de direito em seu aspecto formal dispõem, o ramo do Direito Econômico, oriundo da materialidade dos fatos sociais, adota em especial parâmetros para que se configurem nas relações de mercado, medidas capazes de respeitar a livre concorrência e os valores sociais de caráter fundamental.

A construção dos conceitos de Direito Econômico, é dirigida ainda pela Política Econômica e pela Ordem Econômica. A ciência do Direito Econômico passa a ser aquela que apresenta um sistema de normas jurídicas voltadas à regulamentação da Política Econômica, ou seja, preocupadas com a forma de agir do Estado diante das relações econômicas, bem como são normas que necessariamente devem reverenciar os parâmetros da Ordem Econômica estatuídos constitucionalmente nos artigos 170 e ss. da CF/88. Mais uma vez referidas anotações revelam o caráter intrínseco com que os conceitos do dever-ser, próprios do aspecto lógico do Direito, dirigem tanto a origem de uma ciência, fragmentária do Núcleo Maior, quanto a orientação axiológica que irá deliberar acerca do conteúdo dessa ciência.

Até agora se viu que na construção da estrutura do ramo de Direito Econômico, oriunda das necessidades sociais (caráter material), é indispensável a observância daquilo que a ontologia (o ser) disponibilizou dentro do aspecto formal do conceito de direito. $\mathrm{Na}$ medida em que a ideologia proposta pelos conceitos universalizantes (aspecto formal), denota um sistema fechado de conceitos, vem cada ramo do direito e retiram aquelas 
concepções que orientarão os pensamentos e crenças necessários à realização de conduta determinada.

\section{Características do direito econômico}

Tendo demonstrado que a relação econômica e o objeto do direito econômico, no que se refere em especial ao papel do Estado, são produtos da positiva conexão dos elementos axiológicos (aspecto formal), jurídicos (ponto de conexão) e econômico- sociais (aspecto material), cabe ainda destacar que dessa estrutura, podem-se evidencializar uma série de características que agregam ao Direito Econômico certo individualismo, mantendo sempre seu 'núcleo identidade' com a gama de referenciais fundamentais.

O Direito Econômico é dinâmico. O fenômeno econômico exige uma legislação particularizada (portarias, circulares) para que seja regulamentado, posto que, a utilização apenas de dispositivos genéricos na comporta seu intenso movimento. 0 tempo todo referido ramo do direito tem que rapidamente assimilar o surgimento de novas relações humanas, deve saber conduzir a insistência da desmedida concentração de poder econômico, bem como deve saber reconduzir as moléstias do capitalismo, traduzindo-se assim a evidente necessidade de especificação normativa, bem como sua impossibilidade de codificação.

O Direito Econômico possui mobilidade. A legislação e orientação principiológica que circundam a relação econômica deve ser tal, que o Estado possa retificar inovar ou até retroceder quando o assunto for efetivar o equilíbrio da relação econômica.

O Direito Econômico trabalha com o poder de coerção positiva não sancionatória. 0 Estado 'premia' unidades empresariais para que a política econômica equanimemente implantada, tenha vigência e eficácia.

E por fim o Direito Econômico preocupa-se com a economicidade para o sucesso e beneficiamento da relação jurídica econômica como um todo. Procura-se sempre o melhor resultado tendo como custo o menor sacrifício social possível, mais uma vez, portanto, em prestígio aos referenciais axiológicos envolvidos na construção das concepções do ramo de Direito Econômico (FONSECA, 2004, p. 25). 


\section{0 conceito de direito (em seu aspecto lógico) aplicado ao direito econômico brasileiro (aspecto material)}

\section{Conclusão}

Face a todo exposto, é sobressalente a apreensão dos seguintes aspectos:

I) 0 Direito Econômico Brasileiro com o advento da Constituição Republicana de 1988, define e organiza a relação entre os sujeitos de mercado, suas características e finalidades, a partir de um fundamento axiológico advindo do conceito de direito em seu aspecto formal ( 0 ser);

II) 0 Direito Econômico objetiva o equilíbrio da relação jurídica econômica entre 0 Estado e o Poder Econômico privado, para que a busca pela realização dos interesses de cada um, não se sobreponha às evidencialidades valorativas advindas do texto constitucional, tido como elemento identidade entre o ser e o dever-ser (estrutura formal e material);

III) Quanto ao objeto, o Direito Econômico gerencia a reunião de recursos destinados ao financiamento das necessidades sociais sem, contudo desvincular-se de suas responsabilidades atreladas ao equilíbrio da relação econômica para que esta não objurge princípios sociais da Ordem Econômica (art. 170, CF/88);

IV) Dentre as características que foram se destacando ao longo da evolução da relação econômica, dinamicidade, economicidade, impossibilidade de codificação e mobilidade, nota-se que todas fazem menção ao núcleo identidade existente entre as concepções ontológicas do conceito de direito em seu aspecto formal. A economicidade, por exemplo, ao primar pelo melhor resultado econômico através do mínimo sacrifício social, perpetua a atenção que o Estado garante à manutenção dos valores sociais elencados constitucionalmente uma vez que estão atrelados às definições de justiça social prestigiada nos conceitos universalizados.

V) Verificou-se também, que as orientações axiológicas oriundas do direito ontológico conduzem a construção de todos os ramos do Direito, que ao se estabelecerem sob determinada relação humana, seu objeto e características, mantêm-se clara observância aos ditames fundamentais. 0 equilíbrio da relação econômica perpetrado pelo Estado em proteção aos Princípios e valores da Ordem Econômica, bem como o fato de a finalidade do Direito Econômico estar condicionada à dignidade da pessoa humana, são considerações que revelam o cuidado do Direito Econômico, enquanto ramo do Direito, de reverenciamento às concepções estruturais do Direito em seu aspecto lógico. 
Os aspectos ontológicos orientam cabalmente a construção dos aspectos deontológicos do Direito. 0 'ser' (valores e conceitos para o Direito) mantém íntima e incontestável relação com o 'dever-ser' (direito positivado que se subsume às relações humanas).

É justamente nesse sentido que devem girar as discussões, posicionamentos e decisões oriundas de todas as esferas do Estado no que se refere ao uso e interpretação das atividades econômicas propriamente ditas. Os Poderes, Legislativo, Executivo e Judiciário, democraticamente instituídos tem o inarredável dever de se conduzirem, de tal forma a evitar que os conceitos de Direito em seu aspecto material, ignorem a gama de conceitos de Direito em seu aspecto lógico.

\section{Referências}

FONSECA, João Bosco Leopoldino. Direito Econômico. 5. ed. Rio de Janeiro: Ed. Forense, 2004.

M ONCADA, Luis Cabral de. Direito Econômico. 4. ed. Coimbra: Ed.Coimbra, 2003.

NUSDEO, Fábio. Curso de economia: introdução ao Direito Econômico. 4. ed. São Paulo: Ed. RT, 2005.

VILANOVA, Lourival. Escritos jurídicos e filosóficos. Ed. Axis M undi, 2003. v. 1. 